\title{
MANAGEMENT OF NITROGEN OXIDE EMISSIONS AS A FACTOR OF REDUCING THE LEVEL OF CONTAMINATION AND INCREASING THE SAFETY OF HUMAN LIFE
}

\author{
Dmytro Makarenko \\ Department of chemistry, ecology and expertise technologies \\ National Aerospace University "Kharkiv Aviation Institute" \\ 17 Chkalova str., Kharkiv, Ukraine, 61070 \\ d.makarenko@khai.edu
}

\begin{abstract}
The issues related to the reduction of the level of pollution and the increase in the safety of human life through the control of the operation of coke batteries used in heavy industry are investigated. Data on sources of emissions of harmful substances, including nitrogen oxides, are presented. Different modes of operation of coke batteries are analyzed and mathematical models are obtained, which allow choosing rational operating regimes based on the criterion for minimizing emissions of nitrogen oxides.
\end{abstract}

Keywords: life safety, level of environmental pollution, nitrogen oxides, coke batteries, air excess factor.

\section{Introduction}

Nowadays, the problem of ensuring a reduction in nitrogen emissions is relevant all over the world, since nitrogen compounds $\left(\mathrm{NO}_{\mathrm{x}}\right)$ generally negatively affect human health and the environment. In particular, nitrogen oxides often do not have a smell, and, getting into the human body, bind to hemoglobin. The result is an effect similar to that of carbon monoxide, a transformation into a form that can't transfer oxygen [1]. $\mathrm{NO}_{2}$ irritates the lungs, which can lead to serious health consequences. $\mathrm{NO}_{2}$ combines with water, readily dissolves in fat and can penetrate into the capillaries of the lungs, where it causes inflammation and asthmatic processes.

Since most of the $\mathrm{NO}_{\mathrm{x}}$ emissions in real devices occur in the Zeldovich high-temperature mechanism [2], most of developed methods to reduce these emissions are aimed at reducing the maximum temperature in the combustion zone and reducing the residence time of the reagents in this zone. Methods for reducing $\mathrm{NO}_{\mathrm{x}}$ emissions are subdivided into primary and secondary [3]. The primary measures include measures to optimize the combustion process and the design of devices, resulting in a reduction in $\mathrm{NO}_{x}$ concentration in the exhaust gases. The secondary measures (selective or non-selective catalytic reduction) involve the purification of gases before their release into the atmosphere and entail significant additional costs. The actually used methods are to a large extent due to the existing national emission standards for $\mathrm{NO}_{\mathrm{x}}$ emissions in industrial plants (gas turbine power plants, industrial furnaces), aircraft, cars and devices for the consumer sector, such as boilers or heaters. The more stringent norms are set for emissions, the more expensive the combustion chamber design is and the more difficult it is to manage its working process.

The main ways to reduce NOx emissions are [3-9]:

1. Water vapor injection.

2. Multi-stage combustion.

3. Recirculation of exhaust gases.

4. Combustion of lean (depleted) mixtures).

5. Selective catalytic reduction.

6. Selective non-catalytic reduction.

The production of coke coal in Ukraine is developed quite widely, which causes the urgency of issues related to ensuring environmental safety of its production processes.

Prior to this time, the task of determining the parameters of the operation of coke batteries and modeling their properties for managing the processes of reducing harmful emissions 
to human health, was not fully reflected in the studies. The study of these issues will make it possible to identify the main significant parameters that affect the degree of contamination and to assess the starting point from which values the investigated parameters will have a significant impact. This will allow to optimize the operation of the plants and to reduce the amount of nitrogen oxides in the exhaust gases, which will have a positive effect on the environment and human health.

The aim of research is to analyze the various modes of operation of coke batteries, as well as to select their optimal parameters for determination of the rational operating conditions of the battery by the criterion of minimizing the concentration of nitrogen oxides in the exhaust gases.

To achieve this aim, the following tasks are solved:

- a mathematical model are developed to determine the relationship between the parameters of the air supplied for heating and the concentration of $\mathrm{NO}_{\mathrm{x}}$ in the exhaust gases;

- an analysis is made and opportunities are identified to clarify the requirements for the technological parameters of the coking process to ensure management of their quality and reduce the $\mathrm{NO}_{\mathrm{x}}$ concentration in the exhaust gases.

\section{Materials and methods of research}

The experimental material from [10] is taken as a basic material. It is shown in Table $\mathbf{1}$.

Table 1

The amount of nitrogen oxides formed at different coking parameters

\begin{tabular}{|c|c|c|}
\hline$\alpha$ & $\mathrm{t},{ }^{\circ} \mathrm{C}$ & $\mathrm{c}, \mathrm{mg} / \mathrm{m}^{3}$ \\
\hline \multirow{3}{*}{1,3} & 1200 & 100 \\
\hline & 1320 & 200 \\
\hline & 1440 & 320 \\
\hline \multirow{3}{*}{1,5} & 1200 & 180 \\
\hline & 1320 & 320 \\
\hline & 1440 & 520 \\
\hline \multirow{3}{*}{1,7} & 1200 & 230 \\
\hline & 1320 & 480 \\
\hline & 1440 & 620 \\
\hline
\end{tabular}

Note: $\alpha$-air excess factor supplied for heating; $t$-temperature; $c-N O_{x}$ concentration

The analysis of the obtained data allows to use the plan of the full factorial experiment and determine the values of the output and input variables, taking into account the fact that the number of experiments corresponds to $\mathrm{N}=2^{\mathrm{k}}$. The model is obtained on the basis of the method of constructing of the second order complete central orthogonal central design, the principles of its use for analogous problems are described in $[11,12]$. The values of the input variables are normalized according to the following formulas:

$$
\begin{aligned}
& \mathrm{x}_{1}=\frac{\mathrm{x}_{1}^{*}-\overline{\mathrm{x}}_{1}}{\mathrm{I}_{1}} \\
& \mathrm{x}_{2}=\frac{\mathrm{x}_{2}^{*}-\overline{\mathrm{x}}_{2}}{\mathrm{I}_{2}}
\end{aligned}
$$


where $x_{1}$ and $x_{2}$ - the normalized values of the input variables, $x_{1}^{*}, x_{2}^{*}-$ the natural values of the input variables, $\bar{x}_{1}, \bar{x}_{2}-$ the average values of the input variables $\bar{x}_{1}=1,5 \%, \bar{x}_{2}=1320$, $I_{1}, I_{2}-$ the variation intervals of the input variables $\left(I_{1}=0,2, I_{2}=120\right)$.

The mathematical model is described by a polynomial of the following form:

$$
\mathrm{Y}_{\mathrm{i}}=\mathrm{a}_{0}+\mathrm{a}_{1} \mathrm{x}_{1}+\mathrm{a}_{2} \mathrm{x}_{2}+\mathrm{a}_{3}\left(\mathrm{x}_{1}^{2}-\beta\right)+\mathrm{a}_{4}\left(\mathrm{x}_{2}^{2}-\beta\right)+\mathrm{a}_{5} \mathrm{x}_{1} \mathrm{x}_{2},
$$

where $a_{i}-$ the estimated coefficients, $\beta$ - the parameter that is calculated depending on the number of kernel points of the composite plan $2^{\mathrm{n}-\mathrm{p}}$ of the shoulder of the "star" points $\alpha$ and the number of plan points according to the formula:

$$
\beta=\frac{\sum_{j=1}^{N}\left(x_{i}^{j}\right)^{2}}{N}=\frac{2^{n-p}+\alpha}{N} .
$$

A general view of the data for construction of a central orthogonal composite design is given in Table 2.

Table 2

\begin{tabular}{|c|c|c|c|c|c|}
\hline No of experiment & $\mathrm{x}_{1}$ & $\mathrm{x}_{2}$ & $x_{1}^{2}-\beta$ & $x_{2}^{2}-\beta$ & $\mathrm{Y}_{\mathrm{ij}}$ \\
\hline 1 & $\mathrm{x}_{1}^{\max }$ & $\mathrm{x}_{2}^{\max }$ & $\mathrm{x}_{1}^{\max }-0,6667$ & $\mathrm{x}_{2}^{\max }-0,6667$ & $\mathrm{Y}_{\mathrm{i} 1}$ \\
\hline 2 & $\mathrm{x}_{1}^{\min }$ & $\mathrm{x}_{2}^{\max }$ & $\mathrm{x}_{1}^{\min }-0,6667$ & $\mathrm{x}_{2}^{\max }-0,6667$ & $\mathrm{Y}_{\mathrm{i} 2}$ \\
\hline 3 & $\mathrm{x}_{1}^{\max }$ & $\mathrm{x}_{2}^{\min }$ & $\mathrm{x}_{1}^{\max }-0,6667$ & $\mathrm{x}_{2}^{\min }-0,6667$ & $\mathrm{Y}_{\mathrm{i} 3}$ \\
\hline 4 & $\mathrm{x}_{1}^{\min }$ & $\mathrm{x}_{2}^{\min }$ & $\mathrm{x}_{1}^{\min }-0,6667$ & $x_{2}^{\min }-0,6667$ & $\mathrm{Y}_{\mathrm{i} 4}$ \\
\hline 5 & $\mathrm{x}_{1}^{\max }$ & $\mathrm{x}_{2}^{\mathrm{av}}$ & $x_{1}^{\max }-0,6667$ & $\mathrm{x}_{2}^{\mathrm{av}}-0,6667$ & $Y_{i 5}$ \\
\hline 6 & $\mathrm{x}_{1}^{\min }$ & $\mathrm{x}_{2}^{\mathrm{av}}$ & $\mathrm{x}_{1}^{\min }-0,6667$ & $\mathrm{x}_{2}^{\mathrm{av}}-0,6667$ & $\mathrm{Y}_{\mathrm{i} 6}$ \\
\hline 7 & $\mathrm{x}_{1}^{\mathrm{av}}$ & $\mathrm{x}_{2}^{\max }$ & $\mathrm{x}_{1}^{\mathrm{av}}-0,6667$ & $\mathrm{x}_{2}^{\min }-0,6667$ & $\mathrm{Y}_{\mathrm{i} 7}$ \\
\hline 8 & $\mathrm{x}_{1}^{\mathrm{av}}$ & $\mathrm{x}_{2}^{\min }$ & $\mathrm{x}_{1}^{\mathrm{av}}-0,6667$ & $\mathrm{x}_{2}^{\min }-0,6667$ & $\mathrm{Y}_{\mathrm{i} 8}$ \\
\hline 9 & $\mathrm{x}_{1}^{\mathrm{av}}$ & $\mathrm{x}_{2}^{\mathrm{av}}$ & $\mathrm{x}_{1}^{\mathrm{av}}-0,6667$ & $\mathrm{x}_{2}^{\mathrm{av}}-0,6667$ & $\mathrm{Y}_{\mathrm{i} 9}$ \\
\hline
\end{tabular}

Presentation of data for construction of a central orthogonal composite design

The following formulas are applied to determine the coefficients $\mathrm{a}_{\mathrm{i}}$ :

$$
\begin{gathered}
a_{i}=c_{1} \sum_{j=1}^{N} x^{j} y^{j}, i=1, \ldots, n, \\
a_{i}=c_{2}\left[\left(x_{i-n}^{j}\right)^{2}-\beta\right] y^{j}, i=n+1, \ldots, 2 n, \\
a_{i}=c_{3} \sum_{j=1}^{N} x_{\mu}^{j} x_{\lambda}^{j} y^{j}, i=1, \ldots, n, \mu \neq \lambda, i=2 n+1, \ldots, k,
\end{gathered}
$$




$$
a_{0}=\frac{1}{N} \sum_{j=1}^{N} y^{j}-\beta \sum_{j=1}^{N} a_{n+i} .
$$

In formulas (5)-(8), $\mathrm{c}_{1}, \mathrm{c}_{2}, \mathrm{c}_{3}$ are the coefficients for linear, quadratic and pair interactions of independent variables, respectively, $\mathrm{n}-$ the number of linear terms of the model, and $\mathrm{N}-$ the number of experiments.

For a polynomial of the second degree of the form (4), the values of these parameters are given in Table 3.

\section{Table 3}

The values of parameters for calculation of the coefficients of a mathematical model

\begin{tabular}{ccccc}
\hline $\mathbf{N}$ & $\boldsymbol{\beta}$ & $\mathbf{C}_{1}$ & $\mathbf{C}_{2}$ & $\mathbf{C}_{3}$ \\
\hline 9 & 0,6667 & 0,1667 & 0,5 & 0,25
\end{tabular}

To estimate the accuracy of the obtained model, the sum of the squared deviations of the experimental values of the output variables from the calculated values obtained from the model $\left(\mathrm{S}_{\mathrm{R}}\right)$ and the variance estimates $\left(\mathrm{s}^{2}\right)$ is calculated:

$$
\begin{gathered}
\mathrm{S}_{\mathrm{R}}=\sum_{\mathrm{i}=1}^{\mathrm{N}}\left(\mathrm{y}_{\exp _{\mathrm{i}}}-\mathrm{y}_{\text {calc }_{\mathrm{i}}}\right)^{2}, \\
\mathrm{~s}^{2}=\frac{\mathrm{S}_{\mathrm{R}}}{\varphi},
\end{gathered}
$$

where $\varphi=\mathrm{N}-(\mathrm{k}+1)$ - the number of degrees of freedom, $\mathrm{N}-$ the number of experiments $(\mathrm{N}=9)$, $\mathrm{k}-$ the number of estimated parameters $(\mathrm{k}=5)$.

Evaluation of the significance of the model coefficients is carried out on the basis of Student's t-test:

$$
\left|\mathrm{a}_{\mathrm{i}}\right| \geq \mathrm{t}_{\mathrm{cr}} \mathrm{s}_{\mathrm{i}}
$$

where $t_{c r}$ - the critical value of the Student's distribution for the confidence probability of $95 \%$ and the number of degrees of freedom $\varphi=3, s-$ the standard deviation determined on the basis of formula (10).

\section{Determination of the effect of $\mathrm{NO}_{x}$ concentration with increasing temperature}

As input parameters are taken:

1) air excess factor supplied for heating $\left(\mathrm{x}_{1}\right)$;

2) temperature $\left(x_{2}\right)$.

As the output parameter - concentration of $\mathrm{NO}_{\mathrm{x}}$ in the exhaust gases $\left(\mathrm{y}_{1}\right)$.

An analysis of the initial data shows that in this case there are all the necessary values for constructing a central orthogonal composite design.

The experimental data show that the concentration of $\mathrm{NO}_{\mathrm{x}}$ generally tends to increase with increasing temperature, and also with an increase in the air excess factor supplied for heating. Let's define the features of this effect, as well as the temperature ( $t$ ), from which this effect becomes irreversible. 
Substituting the data in (3), let's obtain a mathematical model describing the influence of the air excess factor supplied for heating and the process temperature on the $\mathrm{NO}_{\mathrm{x}}$ concentration.

This model has the following form:

$$
y=330+158,365 x_{1}+118,357 x_{2}-9,95 x_{1} x_{2}-19,995 x_{1}^{2}+42,5 x_{2}^{2}
$$

Table 4 shows the results of calculations of the lower and upper limits of the intervals, which allow one to assess the significance of the model coefficients.

\section{Table 4}

Results of calculations of the lower and upper boundaries of intervals, which allow one to assess the significance of the model coefficients

\section{Deviation values $\mathbf{t}_{\mathrm{cr}} \mathrm{S}_{\mathrm{i}}$}

Comparison of the numerical values of the estimations of the coefficients and the values given in Table 4, allow to conclude that in this model, the coefficients of quadratic interaction and pair interaction are insignificant coefficients. Thus, the mathematical model can be represented as:

$$
y=330+158,365 x_{1}+118,357 x_{2} .
$$

After the mathematical model has been refined, it can be concluded that the factors "air excess factor supplied for heating" and "temperature" have a significant effect on the value of $\mathrm{NO}_{\mathrm{x}}$ concentration.

The response surface describing the $\mathrm{NO}_{\mathrm{x}}$ concentration values for different temperature values (t) and the air excess factor supplied for heating $(\alpha)$ in the selected planning area is shown in Fig. 1.

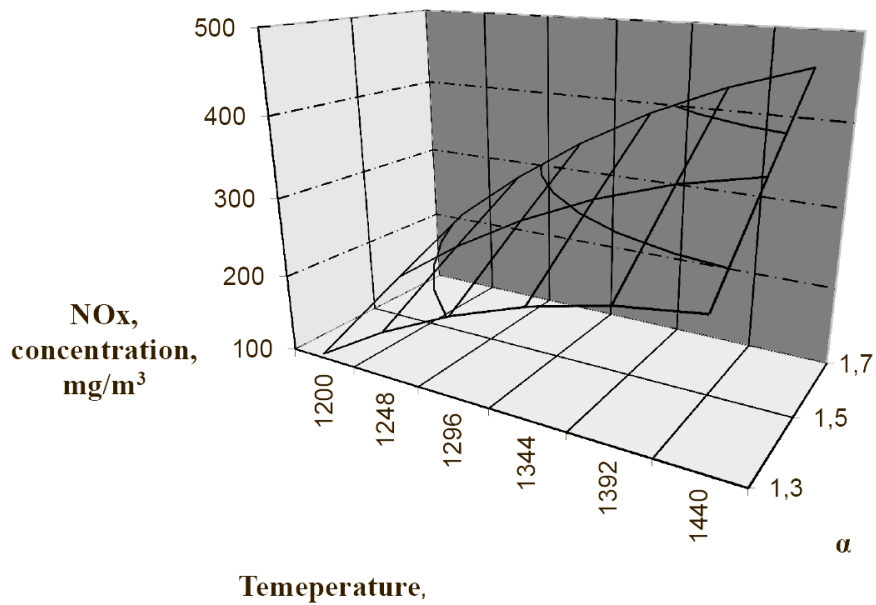

${ }^{\circ} \mathrm{C}$

Fig. 1. The response surface describing the $\mathrm{NO}_{x}$ concentration values for different temperature values $(t)$ and the air excess factor supplied for heating $(\alpha)$ in the selected planning area 
The visual analysis of the response surface also confirms the fact that both the temperature (t) and the air excess factor supplied for heating $(\alpha)$ have a significant effect on the $\mathrm{NO}_{\mathrm{x}}$ concentration. Analyzing the received response surface, it can be concluded that the concentration of NOx increases, both with an increase in the air excess factor supplied for heating, and with an increase in the temperature in the furnace.

\section{Discussion of research results of the effect of $\mathrm{NO}_{\mathrm{x}}$ concentration with increasing temperature}

Analysis of the response surface describing the $\mathrm{NO}_{\mathrm{x}}$ concentration confirms that a significant influence on it is caused by both the air excess factor supplied for heating $(\alpha)$ and the temperature ( $t$ ). The analysis of the received response surface confirms the influence of both input parameters (temperature and air excess factor). Based on the obtained results, it can be concluded that the $\mathrm{NO}_{\mathrm{x}}$ concentration increases with increasing temperature and the air excess factor supplied for heating.

Thus, based on the obtained data, it can be concluded that in order to reduce the $\mathrm{NO}_{\mathrm{x}}$ concentration in the exhaust gases in the coking process, it is necessary to reduce either the temperature or the air excess factor supplied for heating. It should be noted, however, that technical measures to implement the calculated operating modes of the battery involve certain difficulties. In particular, it is about the fact that a decrease in the valuesof the described technological parameters to the specified limits may lead to deterioration in the quality of the coke formation process. It is clear that this is negative from the point of view of obtaining a quality product. Thus, a dilemma arises in the choice of priorities. Obviously, it is necessary to choose a strategy that leads to an increase in the safety of life. Therefore, choosing more safe operating modes of coke batteries, it is necessary to optimize other technological regimes. The latter should not lead to deterioration in the quality of emissions, but not to deteriorate the quality of the finished product.

\section{Conclusions}

As a result of the conducted researches, mathematical models are constructed to determine the relationship between the parameters of the air supplied for heating and concentration of $\mathrm{NO}_{\mathrm{x}}$ in the exhaust gases. The obtained models are regression equations, the estimated parameters of which are obtained by realizing the second order central orthogonal composite design of the full factor experiment. Analysis of these model data and obtained response surfaces shows that both the temperature $(t)$ and the air excess factor supplied for heating $(\alpha)$, have a significant effect on the $\mathrm{NO}_{\mathrm{x}}$ concentration. Analyzing the obtained response surface, it can be concluded that the concentration of $\mathrm{NO}_{\mathrm{x}}$ increases both with an increase in the air excess factor for heating, and with an increase in temperature in the furnace.

The research results can be used to control the processes in coke oven batteries in such way as to ensure a reduction in the concentration of nitrogen oxides $\mathrm{NO}_{\mathrm{x}}$ in the exhaust gases to the maximum permissible value regulated in different countries by the relevant regulatory documents in the field of health protection.

\section{References}

[1] Stamler, J. S., Gow, A. J. (1998). Reactions between nitric oxide and haemoglobin under physiological conditions. Nature, 391 (6663), 169-173. doi: 10.1038/34402

[2] Warnatz, J., Maas, U., Dibble, R. W. (2006). Combustion: Physical and Chemical Fundamentals, Modeling and Simulation, Experiments, Pollutant Formation. Springer, 378. doi: 10.1007/978-3-540-45363-5

[3] Lefebvre, A. H., Ballal, D. R. (2010). Gas Turbine Combustion: Alternative Fuels and Emissions. 3rd Edition. CRC Press, 538.

[4] Smoot, L. D., Hill, S. C., Xu, H. (1998). NOx control through reburning1This mini-review paper was presented, together with a series of other review papers, at the Tenth Annual Technical Conference of the 
Advanced Combustion Engineering Research Center, held in Salt Lake City, Utah, in March 1997.1. Progress in Energy and Combustion Science, 24 (5), 385-408. doi: 10.1016/s0360-1285(97)00022-1

[5] Trehstupenchatoe szhiganie. Available at: http://osi.ecopower.ru/ru/2010-10-18-10-35-22/item/ 82-11225-трехступенчатое-сжигание.html

[6] Retsirkulyatsiya dyimovyih gazov. Available at: http://osi.ecopower.ru/ru/2010-10-18-10-35-22/ item/79-11222-рециркуляция-дымовых-газов.html

[7] Wünning, J. (1997). Flameless oxidation to reduce thermal no-formation. Progress in Energy and Combustion Science, 23 (1), 81-94. doi: 10.1016/s0360-1285(97)00006-3

[8] Selektivnoe kataliticheskoe vosstanovlenie - SKV (SCR). Available at: http://osi.ecopower.ru/ ru/2010-10-18-10-35-22/item/83-1131-селективное-каталитическое-восстановление-—-скв-scr.html

[9] Patent USA No 3900 554. Method for the reduction of the concentration of NO in combustion effluents using ammonia (1973). Assignee: Exxon Research and Engineering Company (Linden, NJ).

[10] Fidchunov, A. L. (2010). Sposobyi snizheniya vyibrosov oksida azota iz dyimovyih trub pri proizvodstve koksa. Energosberezhenie. Energetika. Energoaudit, 7, 53-57.

[11] Demin, D. A. (2011). Methodology of forming functional in the optimal control electric smelting. Technology Audit and Production Reserves, 1 (1 (1)), 15-24.

[12] Mohanad, M. K., Kostyk, V., Demin, D., Kostyk, K. (2016). Modeling of the case depth and surface hardness of steel during ion nitriding. Eastern-European Journal of Enterprise Technologies, 2 (5(80)), 45-49. doi: 10.15587/1729-4061.2016.65454 